\title{
INFORMATION SYSTEM BASED ON IOT AND WEB APPLICATIONS ORIENTED TO FISH FARMING
}

\author{
VIVIANA JiMÉNEZ R., JULIÁN R. CAMARGO L. \& CÉSAR A. PERDOMO CH. \\ Engineering Faculty, Universidad Distrital Francisco José de Caldas, Bogotá, Colombia
}

\begin{abstract}
This document presents the design of a software application whose main function is to report in real-time the measured variables (pH, temperature, pond level) by a hardware device; however, it also offers the way to add and manage the desired users, with different roles (which implies a limitation in the permissions), fish farmers, ponds related to fish farmers and sensors that have been related to those ponds; This to provide a graphic tool to the fish farmer that allows him to make an analysis of the behavior of his crop and to encourage early decision making to reduce losses and improve the production process and the quality of the final product.

KEYWORDS: Backend, Database, Information System, Frontend, Server, WEB Application
\end{abstract}

Received: Sep 24, 2020; Accepted: Oct 14, 2020; Published: Nov 09, 2020; Paper Id.: IJMPERDOCT202034

\section{INTRODUCTION}

In Colombia, fish farming has had a positive development both in terms of things and in the interior of the country, due to the great natural wealth that this territory has; however, the process of cultivating fish for human consumption requires a lot of care and precision since fish are animals very prone to suffer delays or alterations in their breeding, raising and fattening process, due to changes that may occur in their environment.

That is why it is of utmost importance to investigate the physical-chemical parameters associated with the quality of the water of the fish farms, the sensors available in the market to measure such variables, the different wireless communication technologies, the use of the internet of things and web applications, to design and implement a prototype that allows obtaining the value of the temperature, the $\mathrm{pH}$ and water level and visualize them in real-time through a web platform, since normally these fish farms are managed by the rural community for distribution and human consumption and currently have artisanal and considerably inefficient methods of measurement, which can be reflected in the quality of the food that the user will finally receive [1], [2], [3].

This article will emphasize the development of software for the implementation of the mentioned project.

\section{SYSTEM DESCRIPTION}

The development of this project has different stages, which fulfill a specific task and are integrated to ensure the proper functioning of the entire system.

The hardware stage first implements data acquisition, for which the relevant and commercially available sensors are analyzed and chosen, and then implemented in the measurement process (Figure 1). Afterward, these 
sensors are integrated into the embedded system chosen according to their qualities, which in turn has the integration of a LoRa module, which allows communication with a Gateway; this to wirelessly transmit the information obtained by hosting it in a server associated with this same technology.

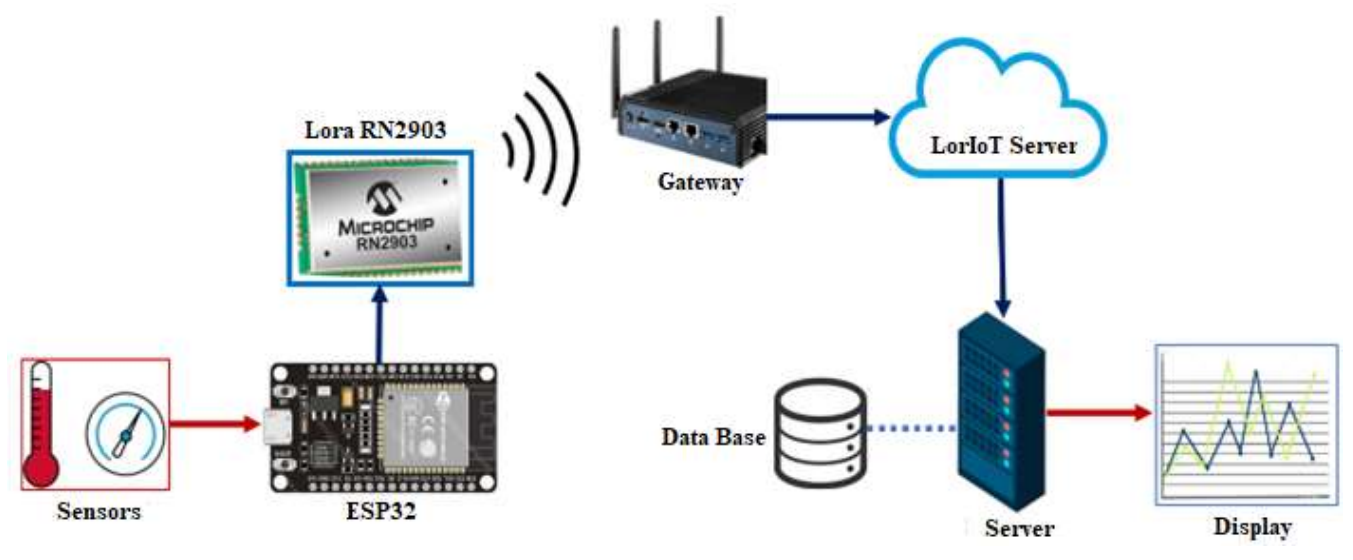

Figure 1: Diagram of the proposed system

Subsequently, software development is proposed that allows the interaction and enrichment of the data obtained by the implemented hardware.

This web application called DataFish offers the final user a series of functionalities that allow him to interact with relevant information from his fish farm and make assertive decisions according to the state of the monitored variables.

The main function of the application is to report in real-time the variables measured by a functional prototype, which has different sensors to obtain the data of the physical-chemical variables associated with the water quality of one or more ponds; however, it also offers a way to add and manage the desired users, with different roles (which implies a limitation in the permits), fish farmers, ponds related to fish farmers and sensors that have been related to those ponds [4].

\section{INFORMATION SYSTEM}

\subsection{Use cases}

Figure 2 shows the use cases of the developed software application [5].

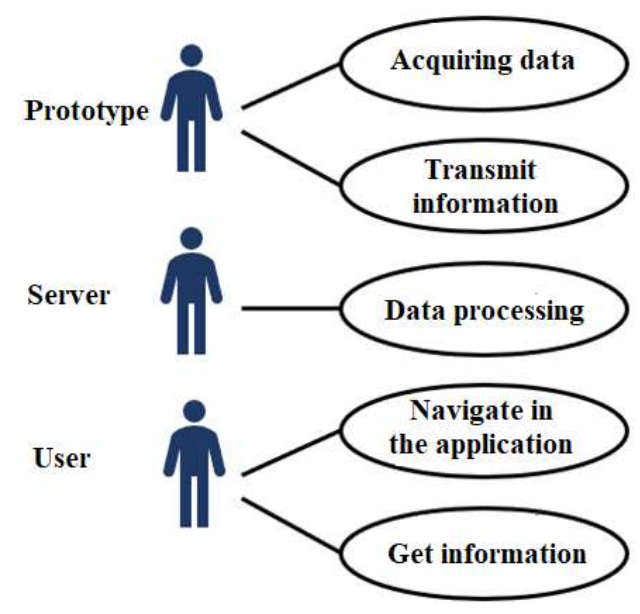

Figure 2: Use cases 
- Acquire data: The prototype implemented in each one of the ponds, which is composed of the different sensors and a development card, is in charge of acquiring the information associated with the quality of the water and making its due digital or analogical adaptation.

- Transmit information: The prototype also contains a LoRa communication module, which sends the information to a gateway with an Internet connection, which in turn sends the data to a cloud server associated with this technology.

- Data processing: The server developed in the project receives requests and performs the processing of input parameters and / or return the necessary, depending on the API that is consulted

- Navigate the application: The end-user can enter the web application, so you can navigate as you like between the different views it offers.

- Obtain the information: The final user can interact with the different functionalities offered by the application, in such a way that he can access the relevant information of the registered users and fish farmers, as well as download some reports with the data of the measured variables, and visualize in real-time the state of these parameters.

\subsection{Roles and Permissions}

Four different types of user roles have been defined for the information system, to restrict and separate the actions that each user can or cannot perform, since in this type of system it is important to have different levels of access to information. This distribution of roles can be seen in Figure 3.

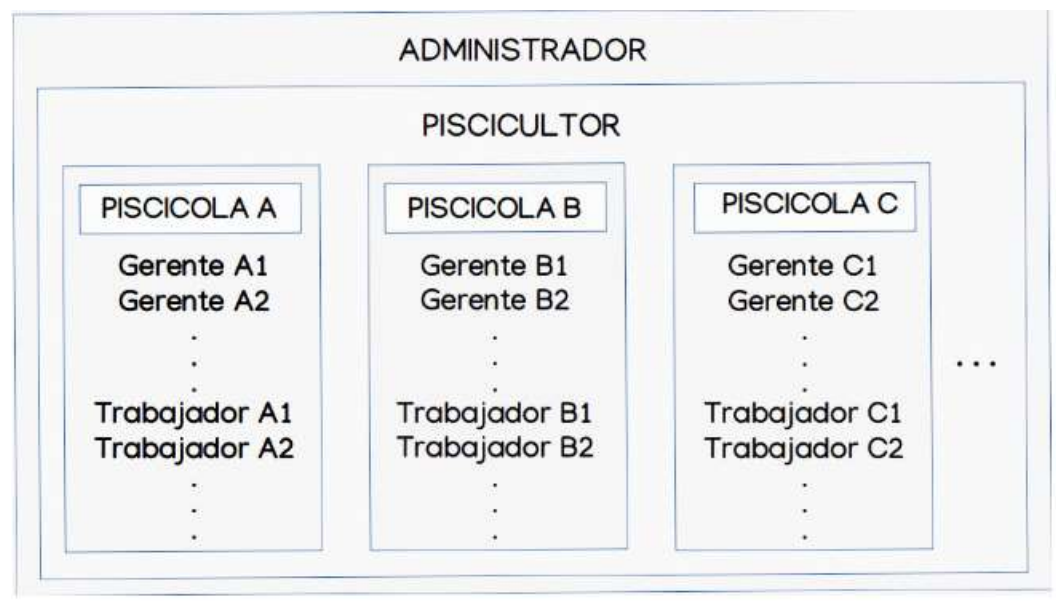

Figure 3: System roles

- The role of the Administrator is the one with the highest level of access to information since he has developer permissions, that is, he is in charge of managing the platform at the software level.

- The role of Fish Farmer is the second-highest access to information, however, has end-user permissions, is responsible for managing their farms and users related to it.

- The Manager role, is the next in the hierarchy list, has access to the total information of the assigned fish farm and the users with a working role assigned to it.

- The Worker role, is the lowest rank in the hierarchy and does not have access to all the functionalities of the platform, but has only permissions to read reports and measurements of its assigned fish farm. 
Each user has different permissions to Create, Read, Update and Delete (CRUD), both users and, fish, ponds and sensors, as appropriate.

Table 1 shows the permissions at the user management level.

Table 1: User management level permissions

\begin{tabular}{|l|c|c|c|c|}
\hline & Admin & Piscicultor & Gerente & Trabajador \\
\hline Admin & CRUD & CRUD & CRUD & CRUD \\
\hline Piscicultor & - & - & CRUD & CRUD \\
\hline Gerente & - & - & - & CRUD \\
\hline Trabajador & - & - & - & - \\
\hline
\end{tabular}

Table 2 now presents the permits at the level of fish farm management, according to the user role.

Table 2: Permissions at the level of fish farming management

\subsection{Database}

\begin{tabular}{|l|c|c|c|}
\hline & Piscicola & Estanque & Sensor \\
\hline Admin & RUD & RUD & RUD \\
\hline Piscicultor & CRUD & CRUD & CRUD \\
\hline Gerente & RUD & CRUD & CRUD \\
\hline Trabajador & R & R & R \\
\hline
\end{tabular}

For this project, it has been installed a MySQL server version 14.14 Distribution 5.7.28, in which it is created a relational database called "db-pisicultivos" because for this information system is very important that the data are related to each other to obtain the hierarchy of roles and the different permissions mentioned above [6], [7], [8]. This database includes seven different tables: Users, Role, Fish, Assignment, Pond, Sensors, Measurements.

Below is a description and structure of each of these tables:

- User table: This table contains all the information that is requested when creating a user, such as a user name, password, an email, and a contact phone number, the latter not being mandatory. This table has a one-to-one relationship with the role table.

- Role Table: This table contains the different roles that users can have, such as Administrator, which refers to the administrator of the whole platform at a software development level; Fish Farmer, which is the highest range of accessibility at an end-user level, can manage users, fish farms, ponds and sensors; Manager, which is a user created by the fish farmer and can manage everything regarding his assigned fish farm and Worker, which is a user created by the fish farmer or manager, who can only view the reporting and measurement functionalities. This table has a one-to-one relationship with the Users table.

- Fish Farm Table: This table contains all the fish farms entered in the system, which will have a name, an approximate or exact location of the fish farm, and a description of it. This table has a many to one relationship with the user table.

- Assignment Table: This table contains the relationship between each user created in the system and their respective assigned fish farm. This table has a many to one relation with the user's table and another many to one relation with the fish farms table.

- Pond Table: This table contains all the ponds entered in the system, which will have a name assigned, the id of the 
fish farm to which they belong and a brief description. This table has a many to one relation with the fish farming table.

- Sensor Table: This table stores all the sensors added to the system, with a name that identifies them, the unit of measurement and a description where you can indicate the type of crop, or the reference of it if you wish. This table has a many to one relationship with the pond table.

- Measurement Table: This table stores all data taken by the sensors implemented in the prototype and contains the sensor id, the measured data and the date when the measurement is taken. This table has a many to one relationship with the sensor table.

Finally, after implementing the tables mentioned above with their respective relationships, you get the entity-relationship diagram, shown in Figure 4.

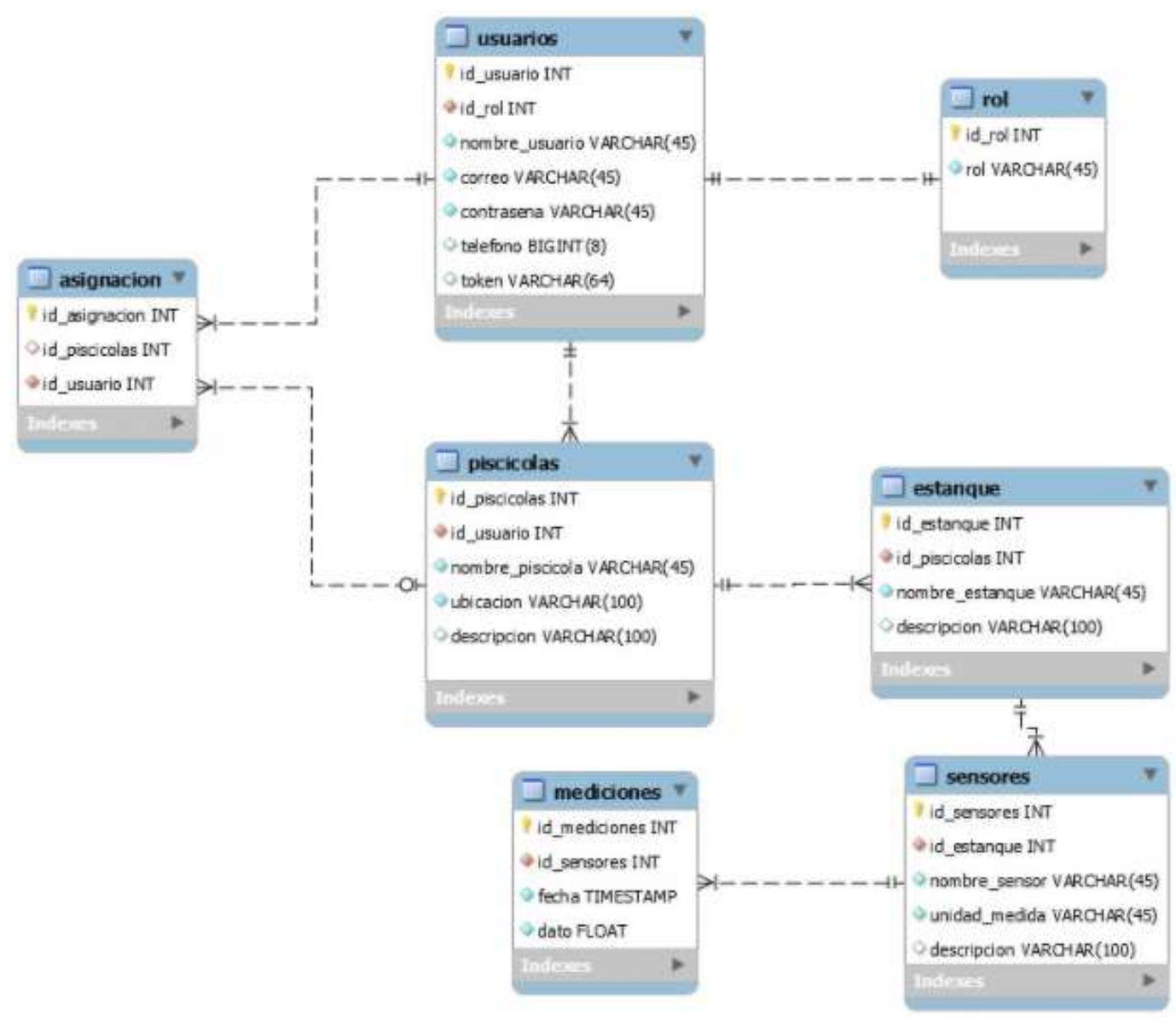

Figure 4: Entity-Relationship diagram

\section{DEVELOPMENT OF THE WEB APPLICATION}

A server has been developed in the backend mode, which implements express.js, works under the Rest API architecture and is linked to a MySQL server that allows hosting the information in a relational database (described in detail in the previous section); and a server in the frontend mode, which implements vue.js to provide a friendly interface with the user, which allows to make queries to that database and visualize interactively and through a web application, the information obtained from the measurements made with the sensors [9], [10], [11]. 


\subsection{Frontend}

For the web application of this project, a server is developed in Frontend mode that implements vue.js to provide a friendly interface with the user [12].

The Frontend is made up of six views that can be accessed through their respective endpoint and a series of components that allow the correct development of the different functionalities of the application. To access the system's information, the user wants to consume and display data from different APIs, making HTTP requests, which is why a connection is made to the server in Backend mode through Axios, a JavaScript library that can be easily executed in the browser.

The application contains four main modules.

\subsubsection{User Management}

In which the logged-in user can access the list of users assigned to the same fish farm. The logged-in user has the option to create new users and edit or delete existing users (Figure 5).

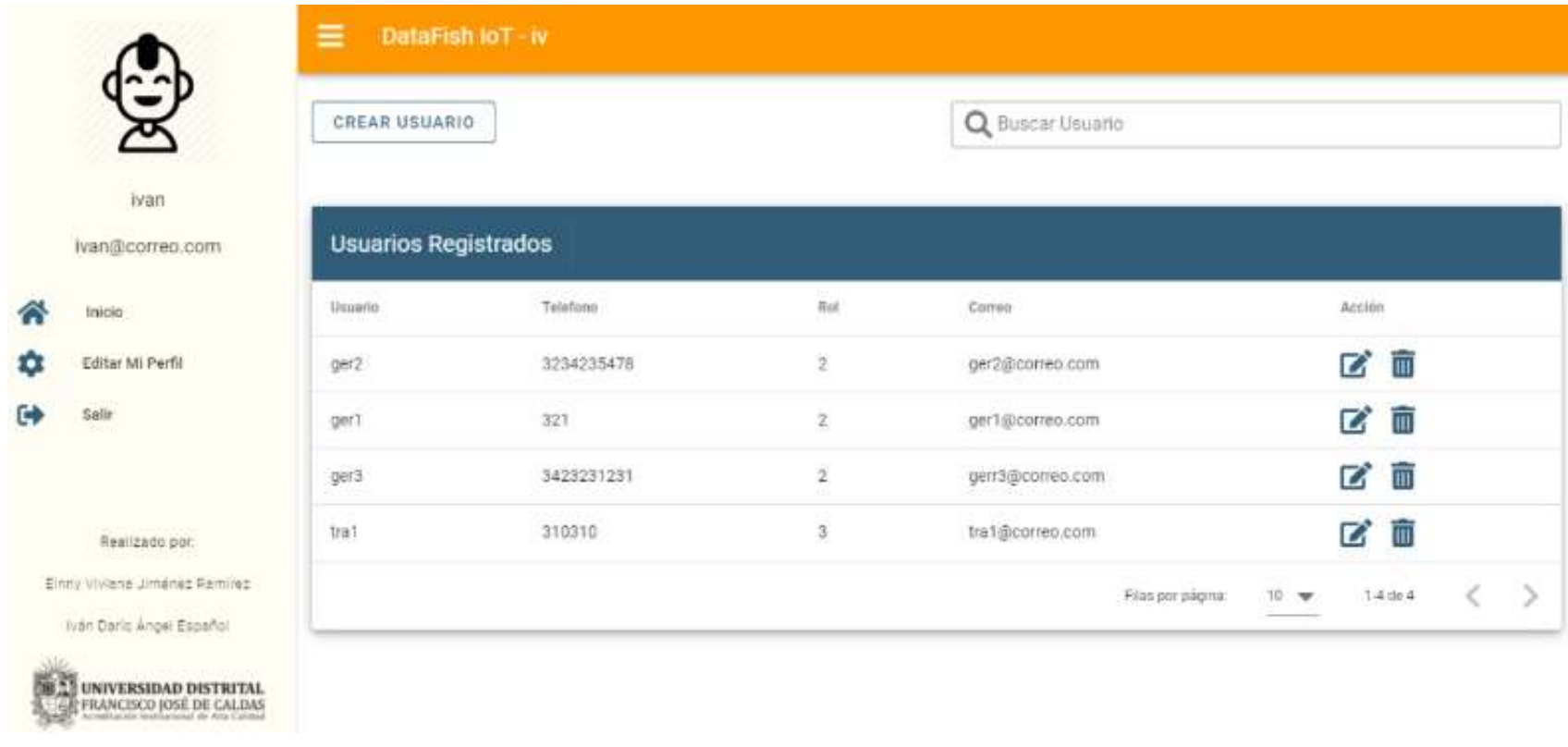

Figure 5: Creating new users

\subsubsection{Fish Farm Management}

Which is the module with the highest number of functionalities in the application, since the logged-in user has access to the list of fish farms that were associated with him, to the ponds associated with those fish farms and therefore to the information of each pond, that is, to each of the sensors registered in the selected pond; in this order of ideas and as it was done in the previous view, the logged-in user can create new fish farms, ponds and sensors, as well as to edit or delete existing fish farms, ponds and sensors (Figure 6). 


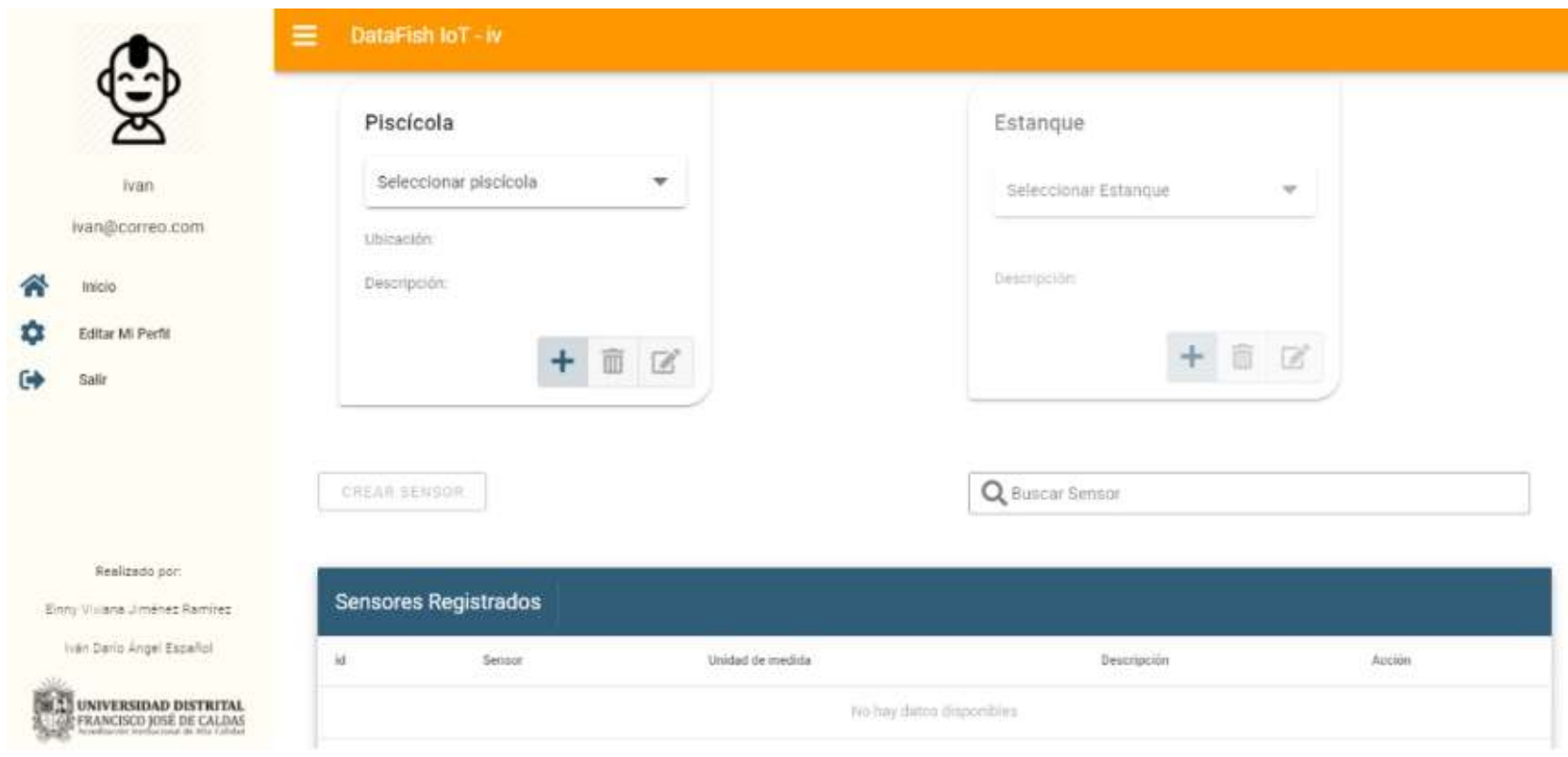

Figure 6: Creating new fish farms, ponds and sensors

\subsubsection{Reports Module}

It is very useful for monitoring and analyzing the status of measured parameters since it allows the logged-in user to select a fish farm and a specific pond and download for this purpose, an indicator report in .csv format with the avg, min and max indicators for the last month, last week, previous day and the current day, and a historical measurement report also in .csv format with the historical measurements of the selected pond and date range (Figure 7).

DataFish

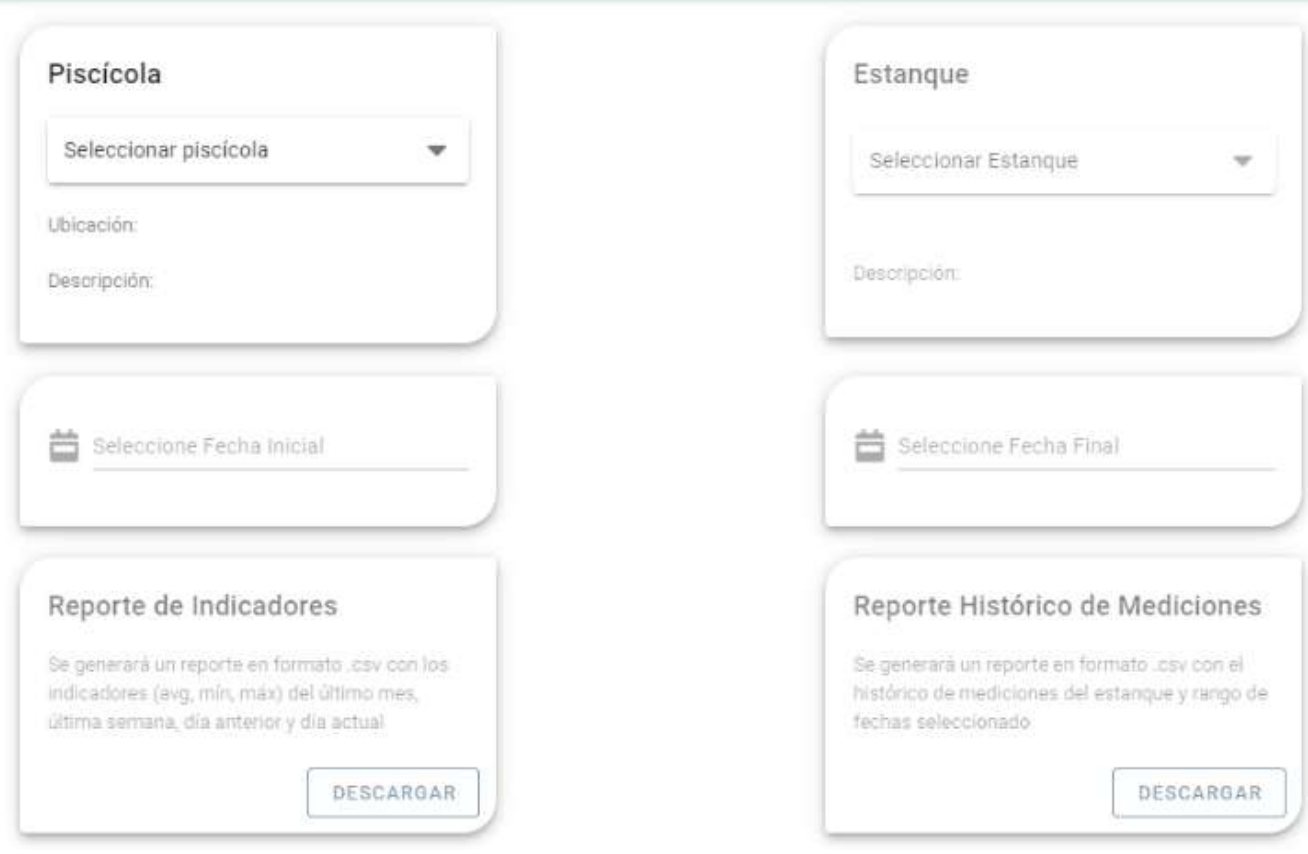

Figure 7: Pond measurement history

\subsubsection{Visualization Module}


In which the logged-in user will be able to monitor in real-time the status of the measured parameters, selecting a fish farm and a certain pond; the user can navigate in the displayed data, selecting the desired date range, to access not only the current data but also the historical measurements stored in the database (Figure 8).

\section{DataFish}

VISUALIZAR

Sensor: temperatura

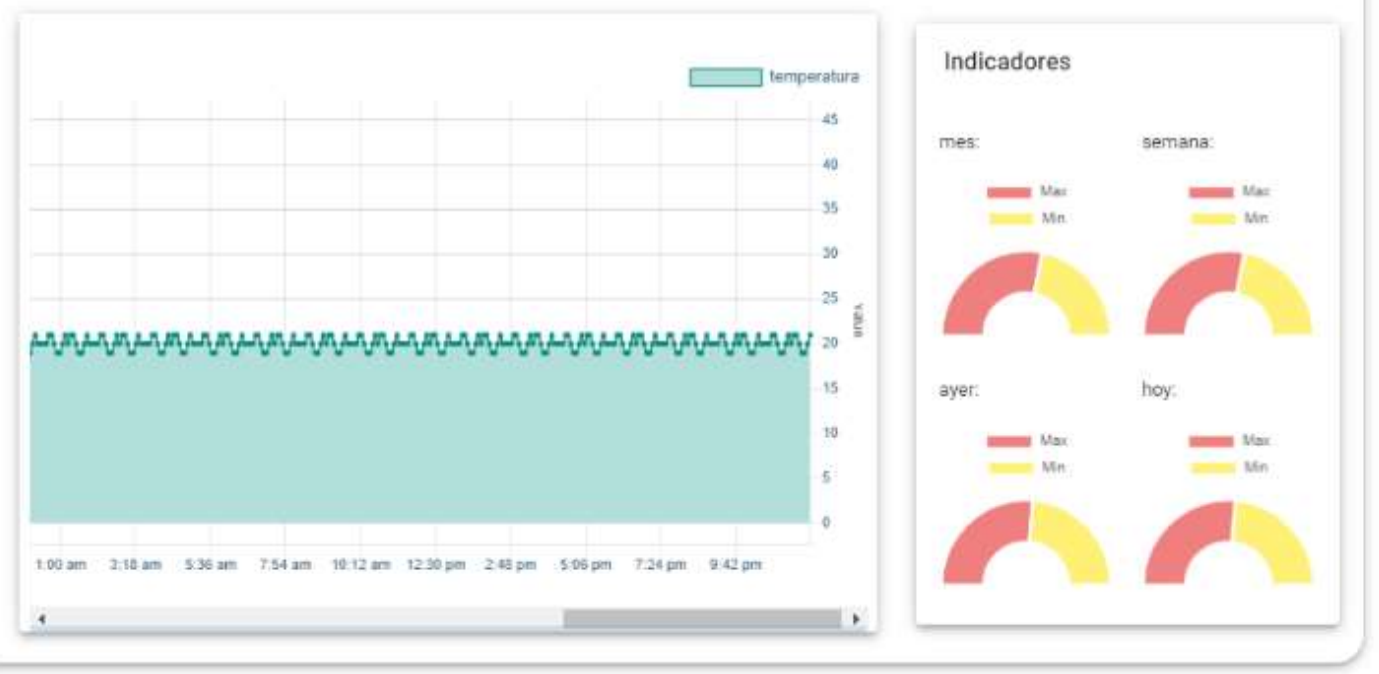

Figure 8: Visualization module

It should be noted that the use of the functions of the different modules is completely linked to the permissions that the user has logged in.

\subsection{Backend}

The backend server of this application has been developed in JavaScript language, under the concept of functional programming and architecture of API Rest and using the FrameWork Express [13].

This server generates the connection with the MySQL server where the database is hosted, in a very simple way, specifying the host, the credentials and the name of the database, this to make all kinds of queries on the different tables, according to what the user wants to do, through the API to which the request is directed.

It is worth mentioning that at the security level, the Message Digest Algorithm 5 (MD5) has been implemented, which is composed of 32 hexadecimal characters, to store and validate the hash of each password created or edited for each user [14].

It is also important to mention that, on this side of the server, token authentication is implemented, that is, in case the login made by the user is successful, the client is considered authenticated and a token is generated and stored in the database along with the user information. Afterward, this token is sent to the Frontend so that it can be used later [15].

With this, every time the client, once authenticated, wants to access a new resource, it will have to send the token to the Backend server, to inform it that it is itself and that it has already been successfully authenticated in a previous step. 
Upon receiving the token, the server will have to verify it and if it finds it valid, it will know that it corresponds to a user of your application, so it can grant access to the resource consulted.

To perform all the relevant actions for the proper functioning of the system, a total of twenty-one APIs have been built, configured with the post method, which receives certain input parameters sent by the Frontend.

Finally, the Backend handles a series of errors for which a unique identification code has been assigned, which is sent to the server on the client-side, to notify if an error has been generated when making the request and to be able to identify it easily.

\section{CONCLUSIONS}

In the measurement methods commonly used in fish farms, intermittent periods occur in the process of monitoring the state of the water; during these periods significant variations can occur that greatly affect the crop, which can be reflected as losses in time and raw materials. Therefore, it is of great importance to implement technologies and systems such as the one developed in this project, since it allows the fish farmer to perform an analysis on the state and behavior of the variables associated with water quality and considerably reduce the periods when the state of the parameters is not known or monitored.

Implementing the concept of a relational database in the system is very useful to store all the information corresponding to the users linked to the system, as well as their respective assigned crops, ponds belonging to the crops and sensors installed in each of the ponds, to maintain a constant commitment to the information obtained and store it in a fully organized and related way.

Nowadays there is a great deal of documentation on different Frameworks that facilitate the development process both at the Backend and Frontend level of a web application, so that implementing them is very useful for the developer, since, due to their practicality, versatility and reuse option, it offers multiple tools that allow him to save time and obtain great results for interacting with the information from both the server and the client-side.

The final result of this project, to graph and know the current values and the behavior that the sensed values present, contributes enormously to the opportune decision making, which allows and is oriented, to minimize expenses and unnecessary losses, as well as to continuously improve the quality of the process and of the food that the user will finally receive.

\section{ACKNOWLEDGMENTS}

The authors would like to thank the Universidad Distrital Francisco José de Caldas and the LASER research group that supported the development and testing of the project.

\section{REFERENCES}

1. Merino, M. A., Salazar, G. \& Gómez. D. (2016). Ministerio de Agricultura y Desarrollo rural - Guía práctica de piscicultura en Colombia. Retrieved from: https://www.aunap.gov.co/wp-content/uploads/2016/04/Guia-Practica-de-Piscicultura-enColombia.pdf

2. de Freitas-Borges, F. (2015). La calidad del agua y las buenas prácticas en acuicultura. Divulgación Acuícola. 23(2):19-24.

3. Peña, A. D. \& Rodríguez, J. M. (2011). Creación y puesta en marcha de una granja piscícola productora de tilapia roja en el departamento del Atlántico. Pontificia Universidad Javeriana, Facultad de Ingeniería, Carrera de Ingeniería Industrial. Retrieved from: https://repository.javeriana.edu.co/bitstream/handle/10554/7444/tesis620.pdf 
4. Polania, N. E., Camargo, J. R. \& Perdomo, C. A. (2020). An Automation Proposal for the Fish Farming Process. International Journal of Mechanical and Production Engineering Research and Development (IJMPERD). 10(3):15825-15838.

5. Ministerio de Agricultura y Desarrollo Rural - Sistema de Información de Gestión y Desempeño de las Organizaciones de Cadenas - SIOC. (2013). Cadena de la Acuicultura. Retrieved from: https://sioc.minagricultura.gov.co/Acuicultura/Documentos/2012-12-31\%20Cifras\%20Sectoriales.pdf\#search=baquero

6. MySQL. (2020). MySQL 8.0 Reference Manual - Including MySQL NDB Cluster 8.0. Retrieved from: https://dev.mysql.com/doc/refman/8.0/en/

7. AWS (Amazon WEB Services. (2020). ¿Qué es NoSQL? Retrieved from: https://aws.amazon.com/es/nosql/

8. Rendón, Y. A. (2019). Academia pragma - Bases de datos relacionales vs. no relacionales. Retrieved from: https://www.pragma.com.co/academia/lecciones/bases-de-datos-relacionales-vs.-no-relacionales

9. Open JS Foundation. (2020). Acerca de Node.js. Retrieved from: https://nodejs.org/es/about/

10. Lucas, J. (2019). Open Webinars -Qué es NodeJS y para qué sirve. Retrieved from: https://openwebinars.net/blog/que-es-nodejs/

11. Civantos, M. (2018). Tribalyte technologies - ¿Qué son las APIS REST? Retrieved from: https://tech.tribalyte.eu/blog-que-esuna-api-rest

12. El abismo de null. (2017). VueJS: The Progressive JavaScriptFramework. Retrieved from: https://elabismodenull.wordpress.com/2017/04/21/vuejs-the-progressive-javascript-framework/

13. Express. (nd). Express - Infraestructura web rápida, minimalista y flexible para Node.js. Retrieved from: https://expressjs.com/es/

14. Melús, D. (nd). Nerion - Algoritmo MD5 - ¿Para qué se puede utilizar? Retrieved from: https://www.nerion.es/blog/cifrado$m d 5 /$

15. Vergara, S. (2019). ITDO - ¿Cuál es el mejor método de autentificación en un API REST? Retrieved from: https://www.itdo.com/blog/cual-es-el-mejor-metodo-de-autentificacion-en-un-api-rest/ 